\title{
Characterization of the Suppressiveness of Hairy Vetch-Amended Soils to Thielaviopsis basicola
}

\author{
B. L. Candole and C. S. Rothrock
}

Department of Plant Pathology, University of Arkansas, Fayetteville 72701.

Accepted for publication 13 November 1996.

\begin{abstract}
Candole, B. L., and Rothrock, C. S. 1997. Characterization of the suppressiveness of hairy vetch-amended soils to Thielaviopsis basicola. Phytopathology 87:197-202.

Factor(s) involved in soil suppressiveness to Thielaviopsis basicola when hairy vetch was used as a green manure were studied in a cotton production system. Soil suppressiveness was assessed in vitro at hairy vetch amendment levels of $0,0.25$, and $0.75 \%$ (wt/wt) by observing chlamydospores, using a nylon fabric technique. Chlamydospore germination in all soils was below $5 \%$, and microscopic examination showed no germ tube lysis or visible propagule destruction. Viability (chlamydospore germination on T. basicola-carrot-etridiazol-nystatin [TB-CEN] medium) was

pressiveness was due to a volatile factor. In a field study, chlamydospore viability in amended soils was reduced by $16 \%$. T. basicola hyphal growth was more sensitive to ammonia than Rhizoctonia solani or Pythium ultimum, and chlamydospore mortality of T. basicola was $100 \%$ in petri dish atmospheres with $0.4 \mathrm{ppm}$ of ammonia (50\% lethal dose $=0.15$ ppm). Soil atmospheric ammonia was 0.08 and $0.10 \mathrm{ppm}$ for 0.25 and $0.75 \%$ amendment levels, respectively, both at 3 and 7 days after incorporation. In the field, 0.11 and $0.14 \mathrm{ppm}$ of ammonia were detected in soil atmospheres 3 and 7 days after incorporation, respectively. The levels of ammonia detected were sufficient to account for the loss in $T$. basicola chlamydospore viability, indicating that ammonia is responsible for the suppressiveness observed.
\end{abstract} reduced by $29 \%$ within $48 \mathrm{~h}$ after hairy vetch amendment. Viability also was reduced in atmospheres of amended soils, suggesting that the sup-
Additional keywords: cover crops.
Hairy vetch (Vicia villosa Roth) is one of a number of legume cover crops that can be planted during the winter in the Southeastern United States in sequence with summer cash crops to reduce soil erosion and improve soil physical and chemical properties (35). In a legume cover crop-cotton (Gossypium hirsutum L.) production system, hairy vetch significantly increased annual seed cotton yield by as much as $162 \mathrm{~kg} / \mathrm{ha}$ compared to winter fallow (40). An estimated 7 to $72 \mathrm{~kg}$ of $\mathrm{N}$ per ha was provided by hairy vetch for the cotton crop when the former was used as green manure $(7,31,40,45)$. Hairy vetch incorporation also improved a number of soil properties, including increased soil nitrogen and organic matter content, increased saturated hydraulic conductivity, increased soil water retention, lower bulk density, and increased water infiltration rate (40).

Cover crops may stimulate or suppress soilborne plant pathogen activity when used as green manures. Pythium damping-off of jack pine (Pinus banksiana) seedlings was increased by green manure crops such as oats (Avena sativa cv. Stormont), rye (Secale cereale cv. Kustro), buckwheat (Fagopyrum esculentum cv. Redstraw), and red clover (Trifolium pratense), whereas Rhizoctonia damping-off was stimulated by rye (48). Populations of Thielaviopsis basicola (Berkeley \& Broome) Ferraris were reduced in soils amended with lucerne (Medicago sativa) (2) and rye (34). In a cotton production system, a reduction in the number of plants killed by Phymatotrichum root rot and increased cotton yields were associated with the incorporation of either hubam (Melilotus alba var. annua) or indica (Melilotus indica) cover crops (29). Green manures or organic amendments also may increase soil populations of other microflora $(36,47)$.

For the cotton seedling disease complex, in which the major causal organisms are T. basicola, Rhizoctonia solani Kühn, and Pythium spp. (15,50), legume winter cover crops have a differ-

Corresponding author: C. S. Rothrock; E-mail address: rothrock@ comp.uark.edu

Publication no. P-1997-0106-03R

(C) 1997 The American Phytopathological Society ential effect on seedling pathogens and the seedling diseases they cause (36). Soil populations of T. basicola, black root rot incidence, and the frequency of pathogen isolation from diseased cotton seedlings were significantly reduced after a hairy vetch winter cover crop compared to a winter fallow treatment (36). In contrast, soil populations of $R$. solani and the frequency of its isolation from diseased cotton seedlings increased after hairy vetch amendment compared to winter fallow (36). Soil populations of Pythium spp. increased after a crop of hairy vetch. However, the frequency of isolation of this pathogen from diseased cotton seedlings did not significantly increase (36).

The mechanism by which hairy vetch suppresses $T$. basicola in hairy vetch-amended soils is unknown. Suppression of fungal propagules in some situations has been associated with volatile compounds $(18,25)$. Volatile compounds have been reported in suppressive or fungistatic soils $(18,19,22)$. In addition, volatile inhibitory compounds are produced by soil microorganisms $(19,20)$. Ko et al. (23) identified the volatile fungistatic substance in alkaline Hawaiian and Colorado soils as ammonia. Ammonia is toxic to many fungi in natural and chitin-amended soils, as well as in soils amended with ammoniacal substances $(12,23,38,39,46)$. The presence of ammonia during decomposition of legume green manures also has been demonstrated (21). Furthermore, the reduction in propagules of some soilborne pathogens due to ammonia in soils amended with organic matter with a low $\mathrm{C} / \mathrm{N}$ ratio has been documented $(17,32,46,51,52)$. Ammonia toxicity has been attributed to its ability to penetrate and disrupt cell membranes $(30,37,49)$.

Based on this information, it is possible that ammonia is present in hairy vetch-amended soils and may play a role in the suppression of T. basicola. The objectives of this paper were (i) to confirm that hairy vetch-amended soils are suppressive to T. basicola, (ii) to demonstrate the nature of the suppressive factor, (iii) to demonstrate the sensitivity of $T$. basicola to ammonia in vitro, and (iv) to determine whether ammonia is present in the atmospheres of hairy vetch-amended soils at suppressive levels. Preliminary reports of this research have been published $(8,9)$. 


\section{MATERIALS AND METHODS}

Soil and hairy vetch tissue preparation. Field-grown hairy vetch, grown at the Delta Branch Experiment Station, Clarkedale, AR, or at the University of Arkansas Experiment Station, Fayetteville, was collected and cut into pieces $\sim 0.5 \mathrm{~cm}$ long and stored below $0^{\circ} \mathrm{C}$ until needed for experiments.

A Dubbs-Dundee complex soil collected from the Delta Branch Experiment Station, Clarkedale, was used in all experiments. The site has a long history of cotton production and different cover crop treatments, including hairy vetch, rye (Secale cereale), and clover (Trifolium incarnatum) (40). The soil was screened through a No. 5 sieve (4.0-mm openings) prior to use. Both autoclaved and nonautoclaved soils were used in the experiments. The former was prepared by autoclaving winter fallow soil twice at $121^{\circ} \mathrm{C}$ for $1 \mathrm{~h}$ over $24 \mathrm{~h}$. Soil water content was adjusted to $18 \%$ (wt/wt on a soil dry weight basis, $-30 \mathrm{~J} / \mathrm{kg}$ ) prior to the first sterilization process.

Propagule preparation. Six-week-old cultures of T. basicola on carrot juice agar (CJA) (100 ml of fresh carrot juice, $12 \mathrm{~g}$ of agar, and $900 \mathrm{ml}$ of deionized water) were flooded with sterile distilled water and decanted to dislodge endoconidia. Chlamydospores, endoconidia, and mycelia were scraped from the surfaces of the cultures with a rubber policeman and suspended in sterile distilled water in a $150 \times 20$-mm test tube containing glass microbeads (No. 50). The suspension was vortexed at high speed for about 1 min to break mycelial fragments, passed through nylon fabric with $53-\mu \mathrm{m}$ openings to remove endoconidia, and the material retained on the fabric was washed several times with sterile distilled water. Chlamydospores were digested with chitinase at 12.5 units of chitinase per $\mathrm{ml}$ by adding $1 \mathrm{ml}$ of a endoconidial and mycelial fragment mixture to $250 \mu \mathrm{l}$ of chitinase solution, $750 \mu \mathrm{l}$ of buffer solution, and about $50 \mathrm{mg}$ of glass microbeads to a 2-ml microfuge vial. The buffer ( $\mathrm{pH} 5.1)$ was $0.6 \mathrm{M}$ citric acid and 1.2 $\mathrm{M}$ sodium phosphate dibasic $\left(\mathrm{Na}_{2} \mathrm{HPO}_{4}\right)(10)$. The suspension was placed on a shaker for $24 \mathrm{~h}$ at 75 strokes per min and vortexed at high speed for $1 \mathrm{~min}$. Chlamydospore chain separation was confirmed by microscopic examination, after which the mixture was transferred to nylon fabric with $25-\mu \mathrm{m}$ openings. After several washings with sterile distilled water, the filtrate was collected and centrifuged at $14,000 \times g$ for $5 \mathrm{~min}$. The pellet, composed of single chlamydospores was resuspended in sterile distilled water and centrifuged again for $5 \mathrm{~min}$. The process of centrifugation and resuspension was repeated three times to remove chitinase. Chlamydospores suspended in distilled water were stored in a refrigerator at 2 to $5^{\circ} \mathrm{C}$.

Direct observation of suppression of $T$. basicola chlamydospores. Amended and nonamended soils were dispensed into $100 \times$ 25-mm plastic petri plates at $90 \mathrm{~g}$ per plate (dry weight). The plates were sealed with a 50.8-mm-wide plastic tape (Sekisui TA Industries, Charlotte, NC) and allowed to incubate for 4 days before soil suppressiveness was assessed. The incubation temperature was $20^{\circ} \mathrm{C}$, and soil matric potential was $-30 \mathrm{~J} / \mathrm{kg}$ (maintained by adding water to restore soils to a constant weight) in all experiments. The procedures for the nylon fabric technique described by Lumsden (28) were used. Nylon fabric with $10-\mu \mathrm{m}$ openings (Tetko, Inc., Depew, NY), cut to fit a Millipore filter holder (Millipore Filter Corp., Bedford, MA), was used to trap chlamydospores. A $25-\mu \mathrm{l}$ aliquot from a chlamydospore suspension containing $10^{7}$ to $10^{8}$ chlamydospores per $\mathrm{ml}$ was pipetted onto nylon fabric mounted over a Millipore filter holder, and a vacuum pump was used to draw the chlamydospores into the nylon fabric. The nylon fabric with trapped chlamydospores was cut into $1 \mathrm{~cm}^{2}$ sections and buried in soil by inserting sections vertically into a slit made in the soil with a spatula and compacting the soil around the nylon fabric (1). The plates were sealed with plastic tape, and after $48 \mathrm{~h}$ of incubation at $20^{\circ} \mathrm{C}$, two sets of nylon fabric sections (three sections per set) from each treatment were retrieved. One set was mounted on a glass slide, stained with aniline blue, and examined under a microscope at $\times 400$ to determine percent germination. The other set was placed on the surface of $T$. basicolacarrot-etridiazol-nystatin (TB-CEN) medium (43) and allowed to incubate for $24 \mathrm{~h}$ at $27^{\circ} \mathrm{C}$. These nylon fabric sections were mounted on glass slides, stained with aniline blue, and examined under a microscope for germinated chlamydospores to determine percent viability. A total of 100 chlamydospores was counted for every nylon fabric section. The experiment was designed in a randomized complete block (RCBD) consisting of three levels of hairy vetch amendment: $0,0.25$, and $0.75 \%$ (wt/wt on a dry weight basis). There were four replications consisting of three subsamples (one nylon fabric section $=$ one subsample) per replicate, and the experiment was performed twice.

To determine the effect of hairy vetch amendment on germination and viability of chlamydospores in the atmospheres of hairy vetch-amended and nonamended soils, 500-ml flasks were filled to capacity with soil. Nylon fabrics containing chlamydospores were placed on water agar (WA) and CJA blocks inside a $4.5 \times 1.5-\mathrm{cm}$ vial. A hole was drilled through the vial cap and lined on the inner surface with a Millipore membrane filter with $0.2-\mu \mathrm{m}$ openings. These vials were buried in the soil. The experiment was performed twice. The experimental design, number of subsamples per replicate, and incubation conditions were the same as above. After incubation, nylon fabrics from CJA were mounted directly on glass slides, stained with aniline blue, and examined under a microscope to determine percent germination. Nylon fabrics from WA were transferred to TB-CEN. After $24 \mathrm{~h}$ at $27^{\circ} \mathrm{C}$, mounts of the nylon fabrics were prepared as per the above procedure and examined under a microscope for germination to determine percent viability.

Data were analyzed as a two factorial experiment in a RCBD by SAS (SAS Institute, Inc., Cary, NC). Trial was treated as a factor, in addition to levels of hairy vetch amendment. Mean separation was performed by LSD at the 5\% level after a significant $F$ test. Results from 0.25 and $0.75 \%$ hairy vetch amendment levels also were averaged and compared with the results from the $0 \%$ amendment level.

Direct observations of $T$. basicola were performed once under field conditions in the long-term cover crop experiment at the Delta Branch Experiment Station, Clarkedale, from 10 to 17 April 1996. The experiment was performed to determine whether observations from controlled environmental studies could be verified in the field. Nylon fabrics with chlamydospores were prepared and incorporated into the soil and examined for chlamydospore germination and viability by the above procedures. The experiment was performed in a completely randomized design with two cover crop treatments (winter fallow and hairy vetch winter cover crop), four replications, and six nylon fabric sections per replicate (three sections each were used to assess chlamydospore germination and viability). Hairy vetch was planted on 13 October 1995 and incorporated into the soil on 8 April 1996. Aboveground biomass was determined to estimate the amount of biomass (dry weight) produced in kilograms per hectare. The aboveground fresh weights were obtained from a $0.84-\mathrm{m}^{2}$ area in at least four areas within a replicate. Dry matter was calculated by assuming that the water content of the tissues averaged $84 \%$ of the fresh weight.

In vitro assay for inhibition of mycelial growth by ammonia. Sensitivity of the seedling disease pathogens $P$. ultimum, $R$. solani, and $T$. basicola to ammonia was examined by an in vitro assay based on inhibition of mycelial growth. Potato dextrose agar (PDA, $10 \mathrm{ml}$ ) was dispensed into one section of plastic bipetri dishes $(100 \times 15 \mathrm{~mm})$. When the agar had solidified, an agar plug ( $4 \mathrm{~mm}$ in diameter) with mycelium of the test fungus (taken from near the edge of a colony on PDA) was placed at the center of the agar surface. Ammonium hydroxide $\left(\mathrm{NH}_{4} \mathrm{OH}\right)$ (29\% ammonia [wt/wt]; Fisher, Fair Lawn, NJ) was used as the source of ammonia. This experiment was designed as a RCBD consisting of 11 levels of $\mathrm{NH}_{4} \mathrm{OH}$ dilutions from 0 to $10 \mu \mathrm{l} / \mathrm{ml}$, with intervals of 
$1 \mu \mathrm{l}$ and three replications. The dilutions were placed in the other section of the petri dishes, using $5 \mathrm{ml}$ per petri dish. The petri dishes were sealed with plastic tape and incubated at $20^{\circ} \mathrm{C}$ for $48 \mathrm{~h}$, at which time radial growth of the colony was measured. The experiment was performed twice. Data from the two trials were combined.

Inhibition of germination and loss of viability of $T$. basicola chlamydospores. The effect of ammonia on chlamydospore germination and viability also was assayed, using nylon fabrics containing chlamydospores according to the above procedures. A series of preliminary in vitro experiments showed $100 \%$ mortality when chlamydospores were exposed to the headspace of petri dishes containing $1 \mu \mathrm{l}$ of $\mathrm{NH}_{4} \mathrm{OH}$ per $\mathrm{ml}$. These experiments were pursued by making further dilutions of $\mathrm{NH}_{4} \mathrm{OH}$. The corresponding ammonia concentrations in the headspace of petri dishes containing different dilutions of $\mathrm{NH}_{4} \mathrm{OH}$ were determined by means of an EM Aquaquant ammonium test kit (EM Science, Gibbstown, NJ). Dilution levels of ammonium hydroxide of 0 to 0.5 $\mu \mathrm{l} / \mathrm{ml}$ in the solutions corresponded to ammonia concentrations ranging from 0 to $0.4 \mathrm{ppm}$ in the petri dish headspace. To determine the effect of headspace ammonia on chlamydospore germination and viability, CJA and WA blocks with nylon fabric sections containing chlamydospores were placed on the inner surface of the lid of a $100 \times 25-\mathrm{mm}$ plastic petri dish. This experiment was designed in a RCBD consisting of six levels of $\mathrm{NH}_{4} \mathrm{OH}$ dilutions ( 0 to $0.5 \mu \mathrm{l} / \mathrm{ml}$, with $0.1-\mu \mathrm{l}$ intervals) and three replications, with three nylon fabric sections or subsamples per replicate. The dilutions were dispensed into the petri dishes at $30 \mathrm{ml}$ per dish. Petri dishes were sealed with plastic tape and incubated at $20^{\circ} \mathrm{C}$ for $48 \mathrm{~h}$. Nylon fabrics from CJA blocks were mounted directly on glass slides and those from WA blocks were transferred to TB-CEN medium to determine percent germination and viability, respectively, according to the above procedures. The experiment was performed twice. Data from the two trials were combined.

Detection and quantification of ammonia in hairy vetchamended soils. Growth-chamber experiments were performed to detect and quantify ammonia in the atmospheres of hairy vetchamended soils. Hairy vetch-amended and nonamended soils were dispensed into 1,000-ml flasks. Each flask was filled with $900 \mathrm{~g}$ (dry weight) of soil. The experiment was conducted as a RCBD with three levels of hairy vetch amendment, as described above, with four replications, and was performed twice.

A ceramic cup (655 round-bottom cups; SoilMoisture Corporation, Santa Barbara, CA) with an inner volume of about $10 \mathrm{ml}$ was placed in the soil (Fig. 1) to collect air from microsites within the soil. Each flask containing soil was covered with plastic film to allow air exchange without altering soil moisture content. The ends of tubes $\mathrm{C}$ and $\mathrm{D}$ of the flask containing the soil were closed during incubation. Incubation temperature was $20^{\circ} \mathrm{C}$, and soil matric potential was maintained at $-30 \mathrm{~J} / \mathrm{kg}$ as described above.

Ammonia in the soil atmosphere was collected by connecting tubes $\mathrm{C}$ and $\mathrm{D}$ to tube $\mathrm{B}$ of a $1,000-\mathrm{ml}$ flask containing $1 \mathrm{M}$ sodium hydroxide solution and tube $\mathrm{E}$ of a $20 \times 50$-mm test tube containing $10 \mathrm{ml}$ of $2 \%$ boric acid (trapping solution), respectively. A 50-ml syringe was attached to tube $\mathrm{F}$ of the test tube with boric acid. Sampling was done by drawing a volume of air equal to the total volume of the ceramic cup, and while this was being done, an equal volume of sodium hydroxide was drawn to fill and purge the ceramic cup of its air content.

Ammonia was trapped as the air from the ceramic cup passed through the boric acid solution. Sampling was done at 3 and 7 days after incorporation. A separate unit was maintained for each sampling time. Because preliminary growth-chamber experiments showed that the results did not vary from one replicate to another within an amendment level, the samples from the four replicates were composited into one sample. The $\mathrm{pH}$ of the samples was adjusted to 12 with $5 \mathrm{~N}$ sodium hydroxide solution and tested for ammonia with an EM Aquaquant ammonium test kit. The Aquaquant am- monium test kit, which is sensitive and specific for ammonium ions, involves a color reaction of indophenol blue, which is produced by the reaction of ammonium ions with hypochlorite and phenol in alkaline solutions. It is assumed that $1 \mathrm{~mol}$ of ammonium ion reacts with $1 \mathrm{~mol}$ of the dye. Quantification of ammonia was done by the lower range test kit ( 0.025 to $0.4 \mathrm{ppm})$.

The amount of ammonia in the soil atmosphere also was quantified under field conditions by superimposing the study on the ongoing cover crop experiment as described above. The ceramic cups were buried $10.2 \mathrm{~cm}$ into the soil within $24 \mathrm{~h}$ after land preparation, which included incorporation of the cover crop. This experiment was performed in a split-plot design, with two winter cover crop treatments (winter fallow and hairy vetch winter cover crop) as the main plot and two sampling times for ammonia ( 3 and 7 days after incorporation) as the subplot, with four replications and three subsamples (ceramic cups) per replicate. Sampling and ammonia determination were done according to the above procedures. Samples from the three subsamples per replicate were composited into one sample and analyzed for ammonia according to the above procedure.

\section{RESULTS}

Direct observation of suppression of $T$. basicola chlamydospores. Chlamydospore chains began breaking into single chlamydospore cells after $4 \mathrm{~h}$ in chitinase solution, the earliest observation made. Almost complete breakage was observed after $24 \mathrm{~h}$. Chitinase did not seem to have any visible deleterious effect on chlamydospores; chlamydospores treated with chitinase germinated readily.

Chlamydospore germination was below $5 \%$ in both amended and nonamended soils. No lysis or visible propagule destruction was observed in these experiments. Viability of ungerminated chlamydospores was significantly reduced from $64 \%$ in nonamended to $41 \%$ in hairy vetch-amended nonautoclaved soils, 0.25 and $0.75 \%$ amendment levels combined, $48 \mathrm{~h}$ after hairy vetch amendment (Fig. 2). Chlamydospore viability also was significantly reduced by an average of $24 \%$ in the atmospheres of nonautoclaved hairy vetch-amended soils (Fig. 3). No significant decrease in chlamydospore viability occurred in atmospheres of autoclaved soils (Figs. 2 and 3).

In the field experiment, soil water potential was -20 to $-30 \mathrm{~J} / \mathrm{kg}$ during the experiment. Aboveground, hairy vetch dry matter ranged from 571 to $4,762 \mathrm{~kg} / \mathrm{ha}$ (dry weight), with an average of 1,968 $\mathrm{kg} / \mathrm{ha}$, which corresponded to $\sim 0.20 \%$ of hairy vetch amendment. Chlamydospore germination in soil was zero. Propagule destruction and germ tube lysis were not observed in the field. Average reduction in chlamydospore viability due to hairy vetch amendment was $16 \%$.

In vitro assay for inhibition of mycelial growth by ammonia. Mycelial growth of $T$. basicola was completely inhibited when

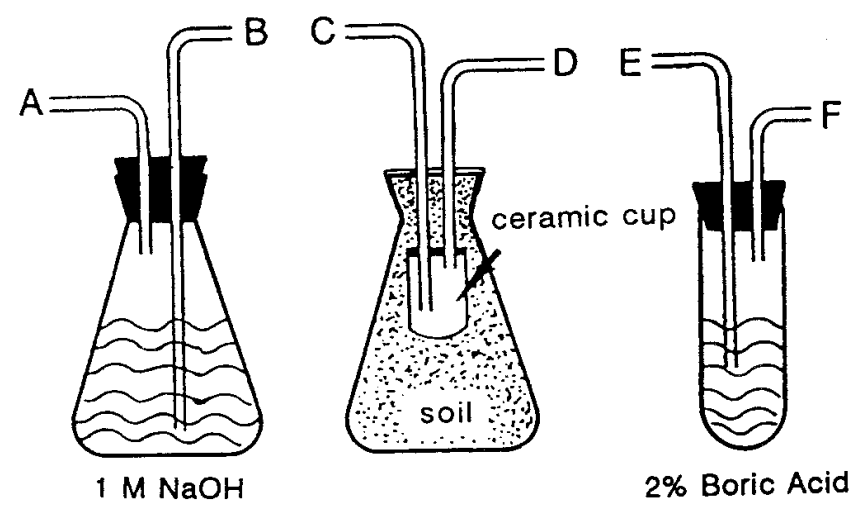

Fig. 1. Schematic diagram of the experimental apparatus used to quantify ammonia in the atmospheres of hairy vetch-amended soils. 


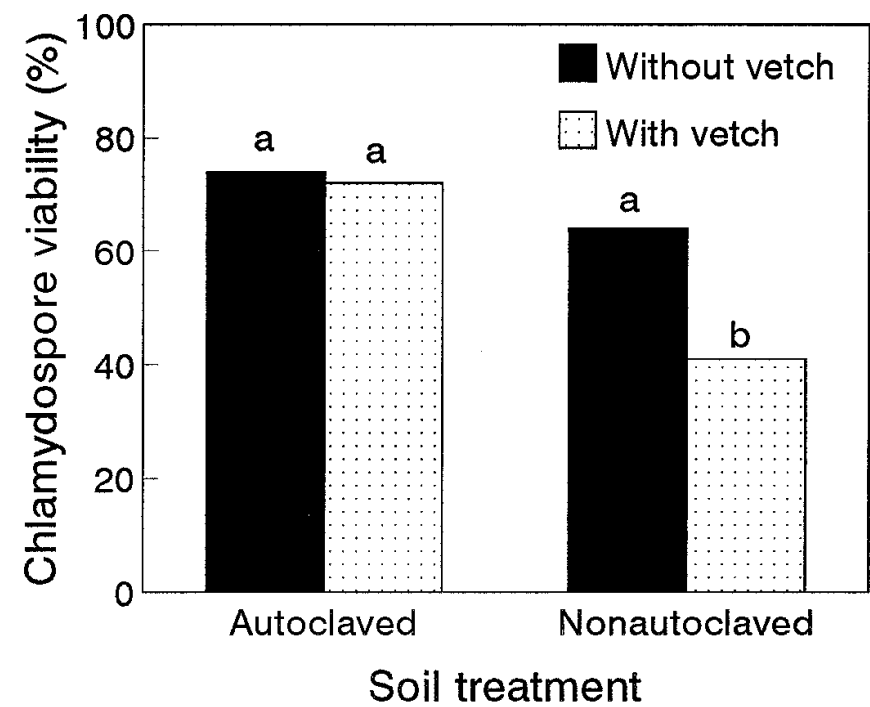

Fig. 2. The effect of hairy vetch amendment on the viability of Thielaviopsis basicola chlamydospores. Within a soil treatment, means with the same letters are not significantly different according to LSD at the 5\% level.

exposed to the atmospheres of petri dishes containing $3 \mu \mathrm{l}$ of ammonium hydroxide solution per ml (Fig. 4). Mycelial growth was $4.3 \mathrm{~mm}$ after $48 \mathrm{~h}$ for $T$. basicola at $0 \mu \mathrm{l} / \mathrm{ml}$. Mycelial growth for $P$. ultimum and $R$. solani was 84 and $54 \mathrm{~mm}$, respectively, in the absence of ammonia. Growth for both of these pathogens dropped to 0 at $6.0 \mu \mathrm{l} / \mathrm{ml}$. The $\mathrm{NH}_{4} \mathrm{OH}$ concentrations that would cause a $50 \%$ reduction $\left(\mathrm{I}_{50}\right)$ in mycelial growth was estimated by regression analyses. The $\mathrm{I}_{50}$ values for $P$. ultimum, $R$. solani, and T. basicola were $2.6,2.7$, and $1.5 \mu \mathrm{l} / \mathrm{ml}$, respectively. Mean separation of the $\mathrm{I}_{50}$ values of the three organisms indicated that the $\mathrm{I}_{50}$ value for $T$. basicola was significantly lower than the $\mathrm{I}_{50}$ values for $P$. ultimum and $R$. solani, whereas the difference in values for $P$. ultimum and $R$. solani were not significant $(P=0.05)$.

Inhibition of germination and loss of viability of $T$. basicola chlamydospores. An ammonia concentration of $0.2 \mathrm{ppm}$ completely inhibited germination of $T$. basicola chlamydospores (Fig. 5). An $\mathrm{I}_{50}$ value (50\% reduction in chlamydospore germination) of $0.08 \mathrm{ppm}$ was estimated for chlamydospore germination. An ammonia concentration of $0.4 \mathrm{ppm}$ resulted in complete loss of chlamydospore viability, with an estimated $50 \%$ lethal dose of $0.15 \mathrm{ppm}$.

Detection and quantification of ammonia in hairy vetchamended soils. In both trials, ammonia concentrations of 0.075 ppm were detected in soil atmospheres at an amendment level of $0.25 \% 3$ and 7 days after hairy vetch incorporation. During the same period, the ammonia level in atmospheres of soils with an amendment level of $0.75 \%$ was $0.1 \mathrm{ppm}$ in both trials.

Ammonia concentrations in the soil atmosphere in the field 3 days after incorporation was 0.025 and 0.113 ppm for winter fallow and hairy vetch treatments, respectively. After 7 days of incorporation, ammonia concentrations were $0.056 \mathrm{ppm}$ and 0.138 ppm for the winter fallow and hairy vetch treatments, respectively.

\section{DISCUSSION}

In both growth-chamber and field studies, the germination of chlamydospores in all soils was either low or zero, whereas most of these chlamydospores germinated when transferred to TB-CEN. Results demonstrated that the significant reduction in activity of the pathogen was the result of a loss in chlamydospore viability due to hairy vetch amendment. Direct observations rule out lysis of the chlamydospores or germ tubes, as suggested by Clough and Patrick (13) and Sneh et al. (42), as the mechanism for the suppressiveness. These observations suggest that substances fungi-

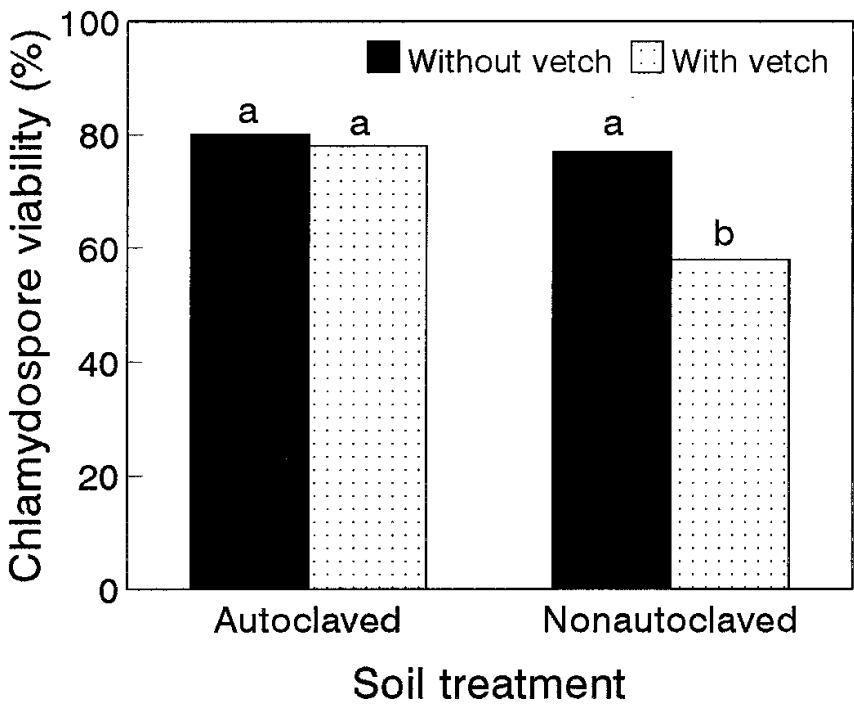

Fig. 3. Viability of Thielaviopsis basicola chlamydospores in the atmospheres of hairy vetch-amended and nonamended fallow soils. Within a soil treatment, means with the same letters are not significantly different according to LSD at the $5 \%$ level.

cidal to T. basicola are produced during decomposition of hairy vetch tissues. In addition, soil atmosphere experiments demonstrate the volatile nature of the suppressive factor.

Germination and viability of chlamydospores of $T$. basicola were more sensitive to ammonia than hyphae. These observations corroborate an earlier report by Steiner and Lockwood (44) that fungal mycelia were less sensitive to soil fungistasis than were corresponding conidia.

Ammonia is frequently measured in the headspace above the soil surface in a closed system $(6,16)$. This closed system also has been used to study the importance of ammonia in the ecology of some soilborne plant pathogens (52). However, the amount of ammonia present in the headspace may not reflect the amount of ammonia present in the soil atmosphere in an open system. Sampling the soil atmosphere or microsites within the soil as measured in this experiment should be more relevant to a field situation and more accurately reflect the role of ammonia or other volatile factors in the activity of soilborne plant pathogens.

Ammonia was detected in hairy vetch-amended soils at concentrations capable of reducing the viability of $T$. basicola chlamydospores. Based on controlled-environment studies, 0.075 and 0.1 ppm of ammonia in the soil atmospheres theoretically would cause about a 25 to $38 \%$ reduction in chlamydospore viability. The average reduction in viability in controlled studies was $29 \%$. Under field conditions, the concentrations of ammonia detected would result in an estimated 38\% reduction in viability 3 days after incorporation in hairy vetch-amended soils. The observed reduction in viability was $16 \%$. Hence, the ability of hairy vetch as a green manure to suppress seedling disease due to T. basicola can be explained by suppressive levels of ammonia generated during microbial decomposition of hairy vetch tissues.

Results from in vitro assays of the three fungal pathogens, which showed $T$. basicola as the most sensitive to ammonia based on mycelial growth, may explain why under field conditions this pathogen was suppressed but Pythium spp. and $R$. solani were not when hairy vetch was incorporated into the soil as a green manure (36). The variability in the sensitivity of different fungal pathogens to ammonia provides limitations on the potential use of legume cover crops that generate ammonia during decomposition to reduce the propagule density of soilborne plant pathogens under field conditions (41) and indicates that ammonia is not capable of suppressing all soilborne plant pathogens. For example, ammonia concentrations of 1 to $100 \mathrm{ppm}$ stimulated germination of conidia 


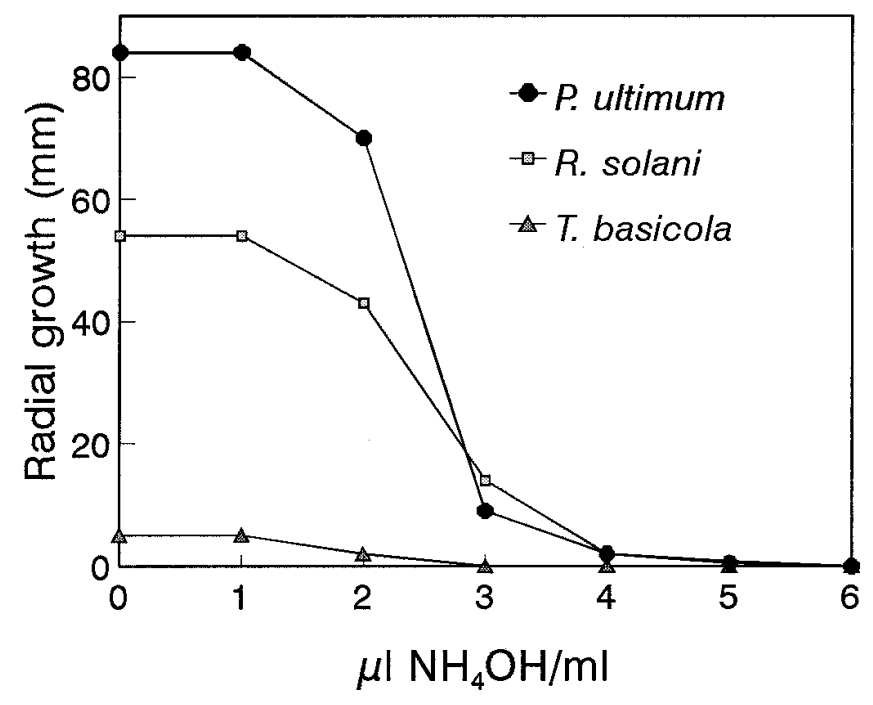

Fig. 4. Mycelial growth of Pythium ultimum, Rhizoctonia solani, and Thielaviopsis basicola after $48 \mathrm{~h}$ when exposed to atmospheres of petri dishes containing different concentrations of ammonium hydroxide. Standard error of the mean for P. ultimum, R. solani, and T. basicola is $14.4,9.1$, and $0.8 \mathrm{~mm}$, respectively.

of Fusarium solani f. sp. phaseoli (33), and low concentrations of ammonia were not toxic to the sclerotia of Macrophomina phaseolina (11). Furthermore, M. phaseolina was less sensitive to ammonia than P. ultimum and T. basicola in urea-amended soils (12). Therefore, for the cotton seedling disease complex, hairy vetch could only be effective in controlling this disease when T. basicola is the most important component of the disease complex (36). Tolerance of fungal propagules such as endoconidia, chlamydospores, zoospores, and mycelia also could vary $(24,26)$. Hence, it is important to know the major survival structure(s) of a target fungal pathogen in the soil.

The use of cover crops in general has some disadvantages (14) aside from increasing population levels of some soilborne plant pathogens and the diseases they cause $(36,47)$. Initial populations of soilborne plant pathogens that are also facultative saprophytes can increase (36) after incorporation of organic matter because of their ability to compete with soil microflora in colonizing these materials (47). Therefore, the risk due to seedling diseases caused by Pythium and Rhizoctonia could be higher if cash crops are planted soon after incorporation of organic materials (47). Phytotoxic volatile substances other than ammonia also are released during decomposition of legume cover crops $(14,32)$ that may predispose plants to infection (34). Volatile ketones emitted by cover crop residues inhibit cotton seedling growth (5). Ammonia by itself can interfere with seed germination and root elongation (3), and it also was reported to contribute to the pathogenicity of a number of bacterial plant pathogens $(4,27)$. Allowing sufficient time after incorporation for cover crop residues to allow initial residue decomposition is important to avoid plant injury due to these phytotoxic substances.

The data confirmed the suppression of T. basicola when hairy vetch was incorporated into the soil as a green manure and that the soil suppressiveness was due to a volatile substance(s). A direct relationship between ammonia concentration in hairy vetch-amended soils and the loss of chlamydospore viability was established.

\section{ACKNOWLEDGMENTS}

Research funding was provided by the U.S. Department of Agriculture Sustainable Agriculture Research Education/Agriculture in Concert with the Environment Program, project LS91-40(44). Published with the approval of the director of the Arkansas Agricultural Experiment Station, Fayetteville.

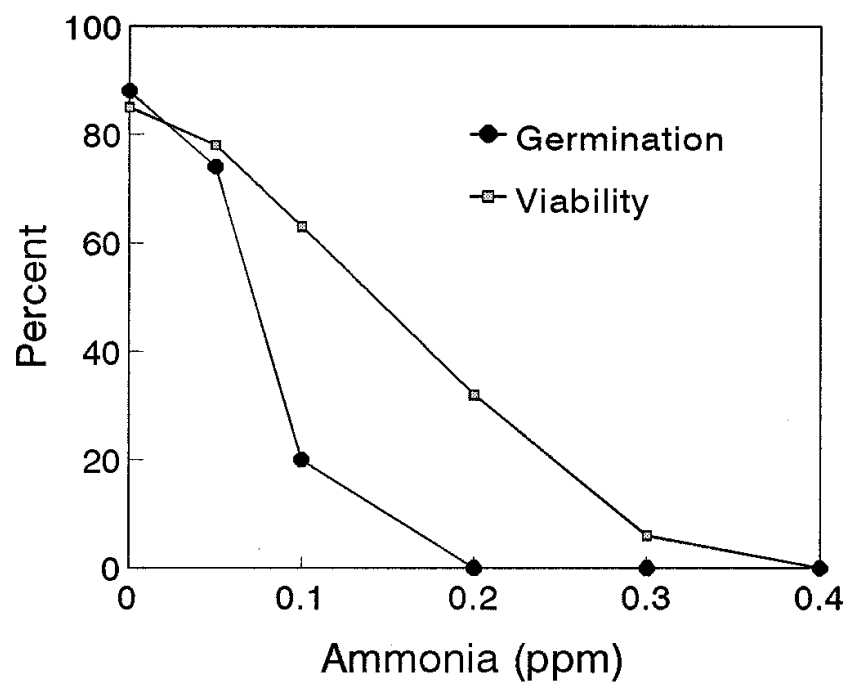

Fig. 5. The effect of different concentrations of ammonia on Thielaviopsis basicola chlamydospore germination and viability after $48 \mathrm{~h}$ of incubation. Standard error of the mean for germination and viability is 15.0 and $13.7 \%$, respectively.

\section{LITERATURE CITED}

1. Adams, P. B. 1967. A buried membrane filter method for studying behavior of soil fungi. Phytopathology 57:602-603.

2. Baard, S. W., and Laubscher, C. 1983. Effect of crop residues and alternative crops on the survival of Thielaviopsis basicola in blackhullinducing soil. Phytophylactica 15:145-148.

3. Baligh, M., Conway, K. E., and Delgado, M. A. 1990. Production of ammonia by Pseudomonas cepacia interferes with seed germination and root elongation. (Abstr.) Phytopathology 80:1048.

4. Bashan, Y., Okan, Y., and Henis, Y. 1980. Ammonia causes necrosis in tomato leaves infected with Pseudomonas tomato (Okabe) Alstatt. Physiol. Plant Pathol. 17:111-119.

5. Bradow, J. M. 1993. Inhibitions of cotton seedling growth by volatile ketones emitted by cover crop residues. J. Chem. Ecol. 19:1085-1108.

6. Bremner, J. M. 1965. Total nitrogen. Pages 1149-1178 in: Methods of Soil Analysis. Part 2, Chemical and Microbiological Properties. Agronomy Monograph 9. C. A. Black, D. D. Evans, L. E. Ersminger, J. L. White, F. E. Clark, and R. C. Dinaver, eds. American Society of Agronomy, Madison, WI.

7. Brown, S. M., Whitwell, T., Touchton, J. T., and Burmester, C. H. 1985. Conservation tillage systems for cotton production. Soil Sci. Soc. Am. J. 49:1256-1260.

8. Candole, B. L., and Rothrock, C. S. 1993. Characterization of suppressiveness of hairy vetch-amended soils to Thielaviopsis basicola. (Abstr.) Phytopathology 83:1418.

9. Candole, B. L., and Rothrock, C. S. 1995. Detection of ammonia in hairy vetch-amended soils and its role in soil suppressiveness to Thielaviopsis basicola. (Abstr.) Phytopathology 85:1130.

10. Christias, C., and Baker, K. F. 1967. Chitinase as a factor in the germination of chlamydospores of Thielaviopsis basicola. Phytopathology 57:1363-1367.

11. Chun, D. A., Filonow, A. B., and Lockwood, J. L. 1984. Interactive effect of ammonia and $\mathrm{pH}$ on $\mathrm{C}$-labelled exudation from fungal propagules. Can. J. Bot. 62:1220-1226.

12. Chun, D., and Lockwood, J. L. 1985. Reductions of Pythium ultimum, Thielaviopsis basicola, and Macrophomina phaseolina in soil associated with ammonia generated from urea. Plant Dis. 69:154-158.

13. Clough, K. S., and Patrick, Z. A. 1976. Biotic factor affecting the viability of chlamydospores of Thielaviopsis basicola (Berk. \& Br.) Ferraris in soil. Soil Biol. Biochem. 8:465-472.

14. Ells, J. E., McSay, A. E., and Workman, S. M. 1991. Toxic effects of manures, alfalfa, and ammonia on emergence and growth of cucumber seedlings. HortScience 26:380-383.

15. Farr, D. F., Bills, G. F., Chamuris, G. P., and Rossman, A. Y. 1989. Fungi on Plants and Plant Products in the United States. The American Phytopathological Society, St. Paul, MN.

16. Fenn, L. B., and Hossner, L. R. 1985. Ammonia volatilization from ammonium or ammonium-forming nitrogen fertilizers. Adv. Soil Sci. 1:123169.

17. Gilpatrick, J. D. 1969. Role of ammonia in the control of avocado root 
rot with alfalfa meal soil amendment. Phytopathology 59:973-978.

18. Hora, T. S., and Baker, R. 1970. A volatile factor in soil fungistasis. Nature (Lond.) 225:1071-1072.

19. Hora, W. H., and Baker, R. 1972. Soil fungistasis: Microflora producing a volatile inhibitor. Trans. Br. Mycol. Soc. 59:148-154.

20. Howell, C. R., Beier, R. C., and Stipanovic, R. D. 1988. Production of ammonia by Enterobacter cloaceae and its possible role in the biological control of Pythium preemergence damping-off by the bacterium. Phytopathology 78:1075-1078.

21. Jansen, H. H., and McGinn, S. 1991. Volatile loss of nitrogen during decomposition of legume green manure. Soil Biol. Biochem. 23:291297.

22. Ko, W. H., and Hora, F. K. 1972. The nature of a volatile inhibitor from certain alkaline soils. Phytopathology 62:573-575.

23. Ko, W. H., Hora, F. K., and Herlicksa, E. 1974. Isolation and identification of a volatile fungistatic substance from alkaline soil. Phytopathology 64:1398-1400.

24. Leach, L. D., and Davey, A. E. 1935. Toxicity of low concentrations of ammonia to mycelium and sclerotia of Sclerotium rolfsii. Phytopathology 25:957-959.

25. Lockwood, J. L. 1977. Fungistasis in soil. Biol. Rev. 52:1-43.

26. Lockwood, J. L., and Filonow, A. B. 1981. Responses of fungi to nutrient-limiting conditions and inhibitory substances in natural habitats. Adv. Microb. Ecol. 5:1-61.

27. Lovrekovick, L., Lovrekovick, H., and Goodman, R. N. 1969. The role of ammonia in wildfire disease of tobacco caused by Pseudomonas tabaci. Phytopathology 59:1713-1716.

28. Lumsden, R. D. 1981. A nylon fabric technique for studying the ecology of Pythium aphanidermatum and other fungi in soil. Phytopathology 71: 282-285.

29. Lyle, E. W., Dunlap, A. A., Hill, H. O., and Hargrove, B. D. 1948. Control of cotton root rot by sweet clover in rotation. Bull. 699. Texas Agricultural Experiment Station, College Station.

30. MacMillan, A. 1956. The entry of ammonia into fungal cells. J. Exp. Bot. 7:113-126.

31. Melville, D. R., and Rasbury, G. E. 1980. The effects of winter cover crops on the production of cotton grown on Norwood very fine sandy loam. Pages 38-48 in: Research Report. Red River Valley Agricultural Experiment Station, Bossier City, LA.

32. Patrick, Z. A., and Toussoun, T. A. 1965. Plant residues and organic amendments in relation to biological control. Pages 440-459 in: Ecology of Soil-Borne Plant Pathogens. K. F. Baker and W. C. Snyder, eds. University of California Press, Berkeley.

33. Pavlica, D. A., Hora, T. S., Broadshaw, J. J., Skogerboe, R. K., and Baker, R. 1978. Volatiles from soil influencing activities of soil fungi. Phytopathology 68:758-765.

34. Reddy, M. S., and Patrick, Z. A. 1989. Effect of host, nonhost, and fallow soil on populations of Thielaviopsis basicola and severity of black root rot. Can. J. Plant Pathol. 11:68-74.
35. Rogers, T. H., and Giddens, J. E. 1957. Green manure and cover crops. Pages 252-257 in: Soil, The Yearbook of Agriculture. A. Stefferud, ed. U.S. Department of Agriculture, Washington, DC.

36. Rothrock, C. S., Kirkpatrick, T. L., Frans, R. E., and Scott, H. D. 1995. The influence of winter legume cover crops on soilborne plant pathogens and cotton seedling diseases. Plant Dis. 79:167-171.

37. Rush, C. M., and Lyda, S. D. 1982. The effects of anhydrous ammonia on membrane stability of Phymatotrichum omnivorum. Mycopathologia 79:147-152.

38. Schippers, B., Meijer, J. W., and Liem, J. I. 1982. Effect of ammonia and other soil volatiles on germination and growth of soil fungi. Trans. Br. Mycol. Soc. 79:253-259.

39. Schippers, B., and Palm, L. C. 1973. Ammonia, a fungistatic volatile in chitin-amended soil. Neth. J. Plant Pathol. 79:279-281.

40. Scott, H. D., Keisling, T. C., Waddle, B. A., Williams, R. W., and Frans, R. E. 1990. Effects of winter cover crops on yield of cotton and soil properties. Ark. Agric. Exp. Sta. Bull. 924.

41. Smiley, R. W., Cook, R. J., and Papendick, R. I. 1972. Fusarium foot rot of wheat peas as influenced by soil applications of anhydrous ammonia and ammonia-potassium azide solutions. Phytopathology 62:86-91.

42. Sneh, B., Holdaway, B. F., Hooper, G. R., and Lockwood, J. L. 1976. Germination-lysis as a mechanism for biological control of Thielaviopsis basicola pathogenic on soybean. Can. J. Bot. 54:1499-1508.

43. Specht, L. P., and Griffin, G. J. 1985. A selective medium for enumerating low populations of Thielaviopsis basicola in tobacco field soils. Can. J. Plant Pathol. 7:438-441.

44. Steiner, G. W., and Lockwood, J. L. 1969. Soil fungistasis: Sensitivity of spores in relation to germination time and size. Phytopathology 59:10841092.

45. Touchton, J. T., Rickerl, D. H., Walker, R. H., and Snipes, C. E. 1984. Winter legumes as a nitrogen source for no-tillage cotton. Soil \& Tillage Res. 4:391-401.

46. Tsao, P. H., and Oster, J. J. 1981. Relation of ammonia and nitrous acid to suppression of Phytophthora in soils amended with nitrogenous organic substances. Phytopathology 71:53-59.

47. van Bruggen, A. H. C. 1995. Plant disease severity in high-input compared to reduced-input and organic farming systems. Plant Dis. 79:976984.

48. Wall, R. E. 1984. Effects of recently incorporated organic amendments on damping-off of conifer seedlings. Plant Dis. 68:59-60.

49. Warren, K. S. 1962. Ammonia toxicity and pH. Nature (Lond.) 195:4749.

50. Watkins, G. M., ed. 1981. Compendium of Cotton Diseases. The American Phytopathological Society, St. Paul, MN

51. Zakaria, M. A., and Lockwood, J. L. 1980. Reduction in Fusarium populations in soil by oilseed amendments. Phytopathology 70:240-243.

52. Zakaria, M. A., Lockwood, J. L., and Filonow, A. B. 1980. Reduction in Fusarium population density in soil by volatile degradation products of oilseed meal amendments. Phytopathology 70:495-499. 